\title{
SCADA FOR PROTOTYPE OF MULTI AREA PARKING SYSTEM BASED ON PLC M221
}

\author{
Agustinus VD Bruin Yudarmawan ${ }^{1)}$, Theresia Prima Ari Setiyani ${ }^{2)}$ \\ Teknik Elektro, Universitas Sanata Dharma, Yogyakarta, Indonesia \\ Email : ${ }^{1}$ agusbruin@gmail.com
}

\begin{abstract}
SCADA for the prototype M221 PLC-based multi-area car parking system is a system for managing several separate car parks on line via ethernet. The system is equipped with HMI as an interface to facilitate operators to monitor system conditions in real-time and the ability to display data on the number of vehicles entering and exiting, counting the number of vehicles parked for one day, and calculating revenue throughout the day. Loop sensor is used to detect vehicles that will enter or exit the parking door. Input from the sensor will be processed by the PLC to move the doorstop motor, indicator lights and update the display on the HMI. The results of a multi-area prototype test process for a car parking system for two parking areas have worked well. The system is able to control the opening and closing of the entrance and exit bars, controlling the indicator lights whether or not the parking area is full, showing the animation of the system process to the HMI in real time, calculating the number of vehicles and calculating the total cost of revenue in each parking area.
\end{abstract}

Keywords : SCADA, PLC M221, Loop Detector, HMI, Car Park

\section{Pendahuluan}

Sistem pengelolaan dan otomasi parkir mobil modern dengan kemampuan pengelolaan beberapa area sekaligus yang terpisah secara on line telah menjadi salah satu hal yang krusial dalam managemen mall, terutama didaerah perkotaan. Sistem parkir modern mampu mendeteksi ada tidaknya mobil yang akan masuk melalui pintu masuk, atau mobil yang akan keluar melalui pintu keluar serta penuh tidaknya area parkir sehingga kontroling terhadap buka tutup gerbang pintu masuk dan lampu indikator penuh tidaknya area parkir akan sesuai dengan kondisi riil saat itu. Sistem parkir modern menuntut adanya kemampuan monitoring sehingga pihak manajemen bisa mendapatkan informasi riil terkait kondisi area parkir saat itu, jumlah mobil yang sedang parkir dan pendapatan yang diperoleh dalam sehari secara real time.

SCADA (Supervisory Control And Data Acquistion) adalah teknologi kendali otomatis berbasis komputer yang digunakan sebagai pemantauan sekaligus juga pengontrolan suatu sistem. SCADA digunakan untuk melakukan proses industri yang kompleks secara otomatis, menggantikan tenaga manusia (karena bisa dianggap berbahaya atau tidak praktis), dan biasanya merupakan proses-proses yang melibatkan lebih banyak faktor-faktor kontrol gerakan cepat yang lebih banyak, dan lain sebagainya, dimana pengontrolan oleh manusia menjadi tidak nyaman lagi [2].

SCADA untuk sistem parkir multi area merupakan sebuah sistem untuk prototype parkir mobil 2 area menggunakan PLC Schneider M221 sebagai kontrol dan HMI sebagai interface antara operator dengan PLC. Adanya HMI akan mempermudah pihak manajemen untuk mengatur dan melihat kondisi sistem secara real time. Penggunaan PLC sebagai kontroler adalah karena PLC memiliki beberapa kelebihan dibanding sistem kontrol konvensional seperti sistem pengkabelan lebih sederhana, pemrograman ulang relatif cepat, adanya record data dan interface yang memudahkan pengguna serta kemudahan pengecekan kerusakan [3]. Penggunaan PLC Schneider seri M221 adalah karena PLC seri tersebut 
memiliki port ethernet sehingga memungkinkan pemantauan dari jarak jauh melalui internet[4].

Saat mobil menuju ke dekat palang pintu masuk, mobil berhenti dan tepat di bawah mobil tersebut terdapat sebuah kumparan kawat yang terhubung ke sensor loop. Setelah sensor membaca bahwa ada data di atas kumpuran kawat tersebut, lalu data tersebut dikirim ke PLC. Setelah PLC menerima data secara langsung dari sensor loop, maka PLC akan menggerakkan palang pintu dan menyalakan lampu led. Lampu led berwarna hijau akan menyala jika keadaan parkir masih belum penuh, dan palang pintu akan terbuka. Sebaliknya ketika lampu led berwarna merah maka keadaan parkir sudah full, palang pintu tidak terbuka. HMI yang menggunakan perangkat lunak Wonderware in Touch akan membaca data sensor yang tersimpan di memori PLC yang digunakan untuk pemantauan secara real time. Selain itu HMI di masing-masing area juga menampilkan jumlah mobil yang sedang parkir, jumlah mobil yang masuk selama seharian, dan perhitungan jumlah pendapatan.

\section{Metodologi Penelitian}

Diagram blok yang digunakan dalam penelitian ini adalah seperti gambar 1 berikut : Gambar

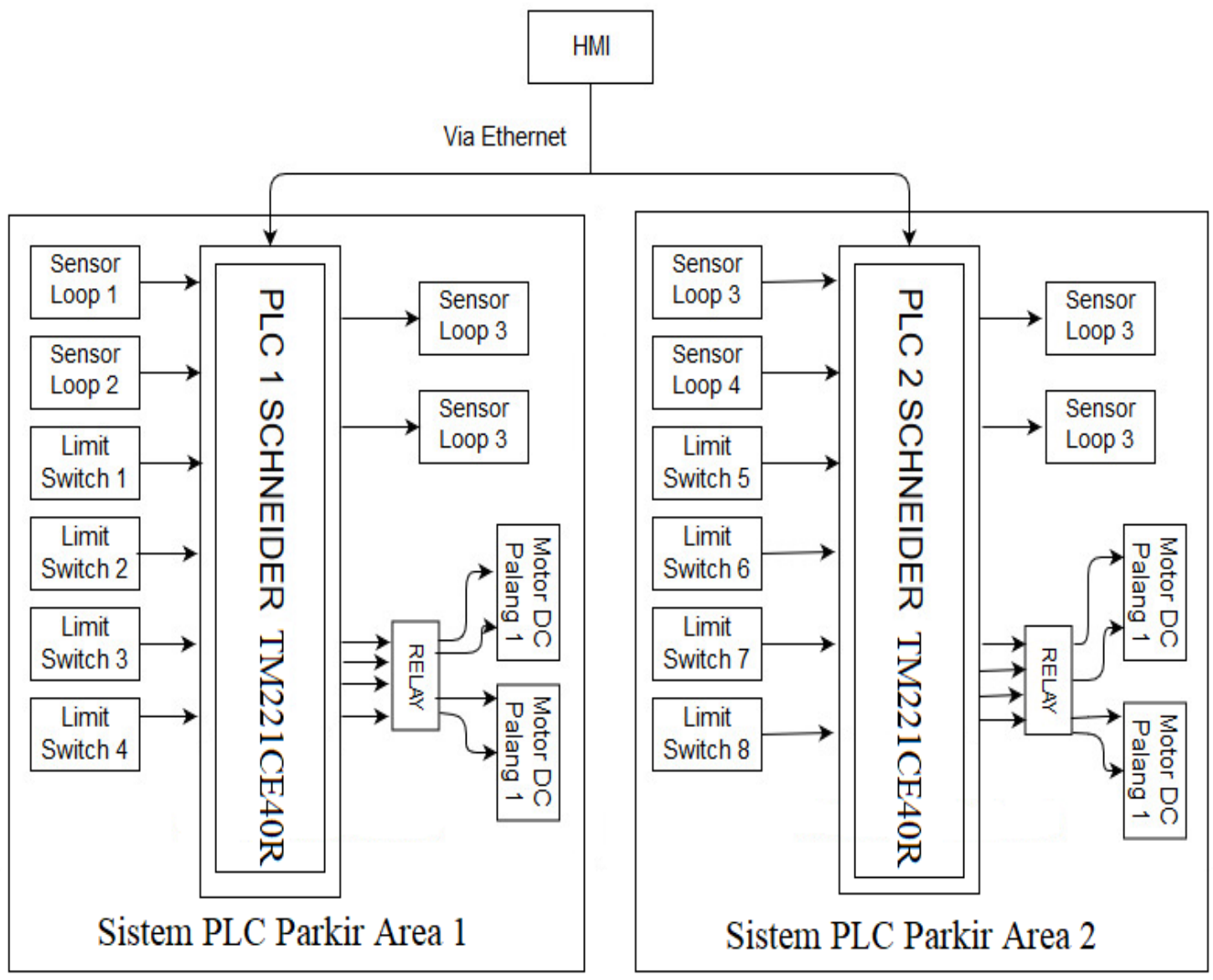

1. Blok Diagram SCADA untuk sistem parkir 2 area berbasis PLC M221

Dengan demikian metode penelitian yang digunakan yaitu :

a. Perancangan dan implementasi perangkat keras prototipe parkir mobil, yang meliputi sistem sensor, motor penggerak palang pintu parkir, dan lampu indikator. Komponen elektronis yang digunakan dapat dilihat pada Tabel 1. 
Tabel 1. Komponen elektronik prototipe palang pintu area parkir mobil multi area

\begin{tabular}{|l|l|}
\hline Piranti & Fungsi atau keterangan \\
\hline Sensor LOOP 1 & Mendeteksi mobil didepan palang pintu masuk area 1 \\
\hline Sensor LOOP 2 & Mendeteksi mobil didepan palang pintu keluar area 1 \\
\hline Sensor LOOP 3 & Mendeteksi mobil didepan palang pintu masuk area 2 \\
\hline Sensor LOOP 4 & Mendeteksi mobil didepan palang pintu keluar area 2 \\
\hline Limit Switch Atas 1 & Sebagai pembatas palang pintu 1 saat naik area 1 \\
\hline Limit Switch Bawah 2 & Sebagai pembatas palang pintu 1 saat turun area 1 \\
\hline Limit Switch Atas 3 & Sebagai pembatas palang pintu 2 saat naik area 1 \\
\hline Limit Switch Bawah 4 & Sebagai pembatas palang pintu 2 saat turun area 1 \\
\hline Limit Switch Atas 5 & Sebagai pembatas palang pintu 3 saat naik area 2 \\
\hline Limit Switch Bawah 6 & Sebagai pembatas palang pintu 3 saat turun area 2 \\
\hline Limit Switch Atas 7 & Sebagai pembatas palang pintu 4 saat naik area 2 \\
\hline Limit Switch Bawah 8 & Sebagai pembatas palang pintu 4 saat turun area 2 \\
\hline Led Hijau dan Merah 1 & Sebagai indikator keadaan parkir kosong dan penuh \\
\hline Led Hijau dan Merah 2 & Sebagai indikator keadaan parkir kosong dan penuh \\
\hline Motor DC (Palang Pintu 1) & Sebagai Penggerak palang pintu 1 \\
\hline Motor DC (Palang Pintu 2) & Sebagai Penggerak palang pintu 2 \\
\hline Motor DC (Palang Pintu 3) & Sebagai Penggerak palang pintu 3 \\
\hline Motor DC (Palang Pintu 4) & Sebagai Penggerak palang pintu 4 \\
\hline Relay & 1. Agar melindungi motor DC dari tegangan \\
& 2. Serlebih dan hubung singkat \\
\hline
\end{tabular}

b. Perancangan dan implementasi perangkat lunak yang meliputi pemrograman ladder PLC untuk kendali motor palang pintu area parkir mobil, dan lampu indikator, serta HMI untuk animasi palang pintu area parkir dan informasi status sensor, dan lampu indikator. Programing PLC menggunakan perangkat lunak SoMachine Basic, sedangkan Programing HMI menggunakan perangkat lunak Wonderware InTouch.

c. Perancangan dan implementasi konfigurasi jaringan Ethernet menggunakan Wonderware MODBUS Ethernet I/O Server (MBENET). MBENET adalah program aplikasi Microsoft Windows yang memungkinkan akses data di PLC Modicon melalui jaringan Ethernet ke PC sehingga laya monitor - sebagai HMI - dapat menampilkan informasi sistem secara real time. Protokol komunikasi melalui Ethernet digunakan untuk menangani elemen data dalam percakapan yang menggunakan konvensi penamaan tiga bagian yang mencakup Application Name, Topic Name, dan Item Name.

Akan diatur juga komunikasi untuk 2 PLC dengan alamat IP yang berbeda. Pengaturan ini dilakukan untuk mengkomunikasikan antara PC dengan PLC. Pengaturan alamat IP dilakukan di masing- masing PC dan didalam jendela Internet Protocol Version 4 (TCP/IPv4) Propertise. PLC 1 memiliki alamat IP yaitu 192.168.1.11 dan PLC 2 memiliki alamat IP yaitu 192.168.1.13.

d. Uji coba dan pengambilan data untuk menguji prototipe yang sudah dibuat untuk melihat hasil kerjanya. Dengan mengambil data berupa, mengambil data kesensivitasan dari suatu kumparan kawat yang tersambung oleh sensor, menghitung jumlah mobil yang masuk maupun mengurangi mobil yang keluar dari parkir, menghitung jumlah mobil yang masuk seharian, menghitung jumlah pendapatan 
seharian. Kemudian membandingkan antara proses pada prototipe dengan animasi pada HMI.

\section{Hasil dan Pembahasan}

Hasil implementasi perangkat keras prototipe area parkir mobil, yang meliputi sistem sensor, motor penggerak palang pintu area parkir, dan lampu indikator, dapat dilihat pada gambar 2 berikut.

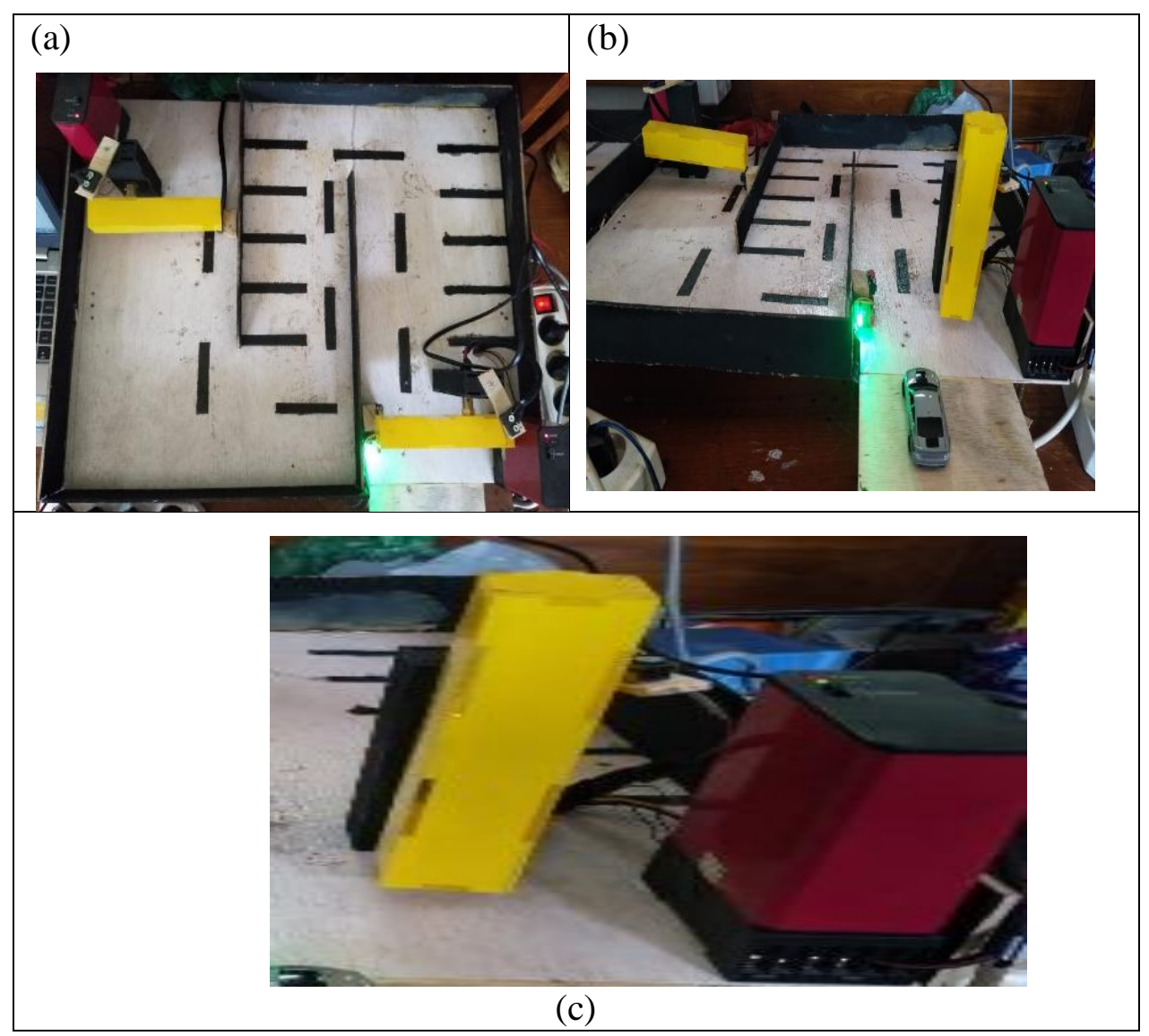

Gambar 2. (a). Hasil implementasi prototype sistem. (b). Kondisi saat sensor mendeteksi kendaraan. (c). Posisi pemasangan Sensor loop

Gambar 2.a. merupakan hasil implementasi prototype area parkir 1 yang didesain untuk menampung 10 buah mobil. Gambar menunjukkan kondisi saat area parkir masih kosong dan tidak ada mobil yang akan parkir maupun keluar sehingga palang pintu masuk dan keluar dalam kondisi tertutup dan lampu indikator hijau menyala yang mengindikasikan area parkir belum penuh. Selanjutnya pada Gambar 2.b tampak bahwa ada sebuah mobil di depan pintu masuk, sehingga palang pintu masuk membuka.

Area parkir yang kedua juga didesain untuk menampung 10 buah mobil, namun area parkir 2 mempunyai bentuk dan ukuran dan letak parkir yang sedikit berbeda dengan area parkir 1.

HMI ditampilkan melalui layar monitor. Melalui HMI dapat dimonitor kondisi sensor, lampu indikator, pergerakan palang pintu dan informasi lainnya. User dapat memilih menu untuk melihat tampilan area parkir 1 atau area parkir 2. Hasil tampilan HMI menu utama saat sudah diaktifkan (a) dan area parkir 1 (b) beserta keterangannya dapat dilihat pada Gambar 3. 


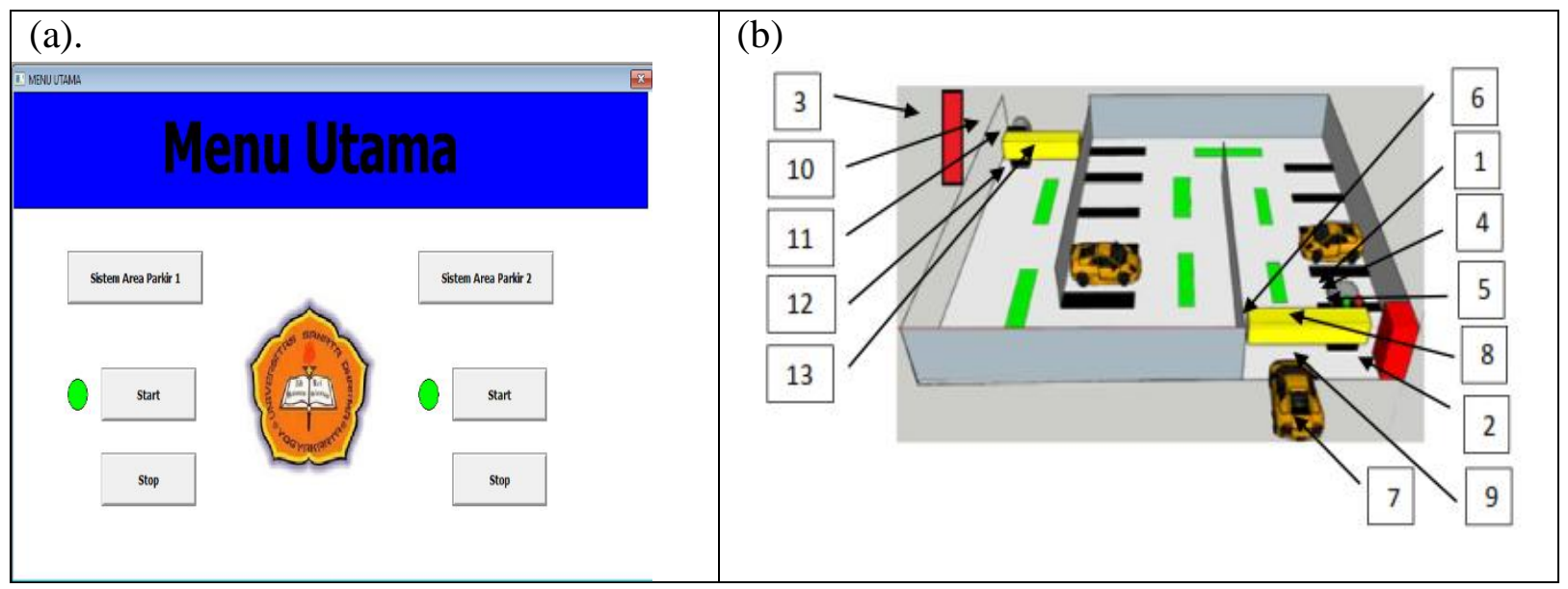

Gambar 3. Tampilan HMI (a) Menu Utama, (b) Area Parkir 1

1. Motor DC Palang 1 (Palang Pintu Masuk Area 1)

2. Sensor Loop 1 (Palang Pintu Masuk Area 1)

3. Sensor Loop 2 (Palang Pintu Keluar Area 1)

4. Led Hijau (Palang Pintu Masuk Area 1)

5. Led Merah (Palang Pintu Masuk Area 1)

6. Palang Pintu 1 (Palang Pintu Masuk Area 1)

7. Car

8. Limit Switch 1 (Palang Pintu Masuk Area 1)

9. Limit Switch 2 (Palang Pintu Masuk Area 1)

10. Motor DC palang 2 (Palang Pintu Keluar Area 1)

11. Limit Switch 3 (Palang Pintu Keluar Area 1)

12. Limit Switch 4 (Palang Pintu Keluar Area 1)

13. Palang Pintu 2 (Palang Pintu Keluar Area 1)

Dari pengamatan saat uji coba dapat diamati bahwa pada saat pengelola telah menekan tombol Start maka sistem menjadi aktif. Kondisi awal diasumsikan tidak ada kendaraan yang berada di depan palang pintu masuk maupun keluar, sehingga palang pintu dalam kondisi tertutup, lampu indikator hijau menyala, dan lampu indikator merah mati. Pada saat sensor loop mendeteksi adanya kendaraan yang akan masuk ke area parkir, maka palang pintu akan membuka, lampu indikator hijau menyala, dan lampu indikator merah masih mati. Saat mobil telah masuk area parkir sensor loop menjadi tidak mendeteksi kendaraan sehingga palang pintu menutup, lampu indikator hijau masih menyala, dan lampu indikator merah mati. HMI akan menampilkan jumlah mobil yang sudah masuk beserta uang parkir yang akan diperoleh. Kondisi ini akan berulang tiap kali ada mobil terdeteksi ada di depan pintu masuk dan jumlah mobil yang berada di area parkir belum mencapai 10 . Hal yang sama akan terjadi pada palang pintu keluar. Bedanya saat mobil sudah keluar informasi jumlah mobil yang ada dalam area parkir akan berkurang 1 .

Lampu indikator merah akan menyala saat kondisi parkir full (berjumlah 10) dan palang pintu masuk tidak akan membuka meskipun sensor mendeteksi ada mobil di depan pintu masuk. Saat ada mobil mau keluar dari pintu keluar dan jumlah didalam area parkir memiliki 10 kendaraan, palang pintu keluar membuka, lampu indikator hijau kembali menyala, dan lampu indikator merah kembali mati. Demikian akan berlangsung secara terus menerus sampai pengelola menekan tombol Stop. Proses yang sama juga terjadi pada area parkir kedua. 
Beberapa hasil tampilan di area parkir dan HMI dapat dilihat pada pada Tabel 2 untuk area parkir 1 dan Tabel 3 untuk area parkir 2.

Tabel 2. Data Tampilan HMI dan Area Parkir 1

\begin{tabular}{|c|c|c|}
\hline Kondisi & Tampilan HMI & Tampilan Area Parkir \\
\hline $\begin{array}{l}\text { Kondisi } \\
\text { tidak } \\
\text { adanya } \\
\text { kendaraan } \\
\text { didepan } \\
\text { palang } \\
\text { pintu } \\
\text { masuk } \\
\text { dan } \\
\text { keadaan } \\
\text { sudah full } \\
\text { sehingga } \\
\text { palang } \\
\text { pintu } \\
\text { tidak bisa } \\
\text { terbuka }\end{array}$ & $\begin{array}{l}\text { SISTEM AREA PARIAR 1 } \\
\text { Tampilan palang menutup, baik di } \\
\text { pintu masuk maupun keluar. Gambar } \\
\text { mobil tertampil 10. Lampu indikator } \\
\text { merah menyala. Jumlah mobil = 10, } \\
\text { jumlah mobil yang telah parkir dalam } \\
\text { sehari = 10 sehingga uang parkir = Rp } \\
\text { 50.000 . }\end{array}$ & $\begin{array}{l}\text { Palang pintu dalam keadaan tertutup } \\
\text { Lampu merah menyala menandakan } \\
\text { bahwa area parkir sudah penuh. }\end{array}$ \\
\hline $\begin{array}{l}\text { Kondisi } \\
\text { adanya } \\
\text { kendaraan } \\
\text { didepan } \\
\text { palang } \\
\text { pintu } \\
\text { keluar. }\end{array}$ & $\begin{array}{l}\text { SISTEM AREA PARKIR 1 } \\
\text { Sensor on karena mendeteksi adanya } \\
\text { kendaraan. Ada animasi pergerakan } \\
\text { Palang Pintu membuka. Tampilan } \\
\text { jumlah mobil yang masuk seharian } \\
\text { tetap = 10, namun tampilan jumlah } \\
\text { mobil yang sedang parkir berubah } \\
\text { menjadi } 9\end{array}$ & $\begin{array}{l}\text { Palang Pintu keluar membuka. } \\
\text { Lampu hijau kembali on } \\
\text { menandakan area parkir belum } \\
\text { penuh. }\end{array}$ \\
\hline
\end{tabular}

Dari Tabel 2 dapat diamati bahwa jika kondisi area parkir 1 sudah penuh, maka Palang pintu masuk dalam keadaan tertutup dan tetap tertutup meskipun sensor loop mendeteksi ada mobil. Lampu merah menyala menandakan bahwa area parkir sudah penuh. Lampu hijau akan menyala saat telah ada mobil yang keluar. 
Tabel 3. Data Tampilan HMI dan Area Parkir 2

\begin{tabular}{|l|l|l|l|l|l|}
\hline \multicolumn{1}{|c|}{ Kondisi } & \multicolumn{3}{|c|}{ Tampilan HMI } \\
\hline $\begin{array}{l}\text { Kondisi } \\
\text { awal, } \\
\text { tidak ada } \\
\text { mobil di } \\
\text { palang } \\
\text { pintu } \\
\text { masuk }\end{array}$ & &
\end{tabular}

Tabel 3 menampilkan kondisi awal. Sensor dipalang pintu masuk tidak mendeteksi kendaraan sehingga sensor dan motor Dc masih off, kondisi led merah masih off, led hijau on, untuk menghitung jumlah seharian, jumlah mobil di area parkir dan biaya pendapatan masih bernilai 0 . Ketika sensor mendeteksi kendaraan, maka sensor berkondisi on kemudian menggerakkan motor Dc untuk membuka palang pintu, led merah masih kondisi off, led hijau kondisi on, kemudian untuk menghitung jumlah seharian, jumlah mobil di area parkir bernilai 1, dan biaya pendapatan sekarang menjadi Rp 5.000. Ketika didalam parkir terdapat 10 kendaraan maka dinyatakan keadaan sudah full yang dimana terjadi perubahan terhadap led merah kondisi on dan led hijau kondisi off. Berdasarkan hasil pengamatan yang sudah dilakukan saat percobaan, hubungan antara tampilan HMI dengan plant di sistem area parkir 
sudah berjalan dengan baik karena kondisi komponen I/O keduanya sama dengan tingkat keberhasilan $100 \%$.

\section{Kesimpulan}

Dari hasil pengujian alat prototipe sistem parkir mobil multi area berbasis PLC yang dapat di monitor melalui HMI dapat diambil kesimpulan :

1. Komunikasi yang terjadi antara PLC 1 dan PLC 2 dengan HMI sudah berjalan dengan baik, dan komunikasi antara PLC 1 dengan PLC 2 menggunakan kabel LAN melalui switch hub yang seterusnya diatur dengan MBENET sudah berjalan dengan baik.

2. Tampilan HMI berjalan dengan baik karena sesuai dengan prototipe yang sudah dirancang.

3. Sensor loop bekerja dengan baik dalam mendeteksi mobil yang akan masuk maupun keluar dari area parkir.

4. SCADA untuk prototipe sistem parkir mobil multi area berbasis PLC M221 dapat dipantau secara real time dan ada record data di dalam SCADA berupa perhitungan jumlah kendaraan yang masuk maupun keluar, menghitung jumlah mobil yang masuk seharian dan menghitung jumlah pendapatan sudah berjalan dengan baik.

\section{Ucapan Terima Kasih}

"Penulis Th. Prima Ari dan Agustinus VD Bruin Yudarmawan. Mengucapkan terima kasih kepada LPPM USD yang telah memberikan dukungan finansial melalui Hibah Penelitian Internal tahun 2019".

\section{Daftar Pustaka}

[1] Electric, S. (n.d.). Schneider Electric. Retrieved Oktober 25, 2018, from https://www.se.com/ww/en/product/TM221CE24R/controller-m221-24-io-relay-ethernet/

[2] IEBHE. (2017). Ndoware. Retrieved September 14, 2009, from https://ndoware.com/kelebihan-plc.html

[3] Ulin, C. (2017, Oktober 29). SCRIBD. Retrieved from https://www.scribd.com/document/362935493/Apa-Manfaat-SCADA-Bagi-Anda

[4] Utama, A. D. (2010). Perancangan Sistem Perparkiran Kendaraan Roda Empat Menggunakan Teknologi RFID. Surakarta. Retrieved Januari 5, 2010, from https://core.ac.uk/download/pdf/12351861.pdf 